TITLE:

\title{
Annual periodicity of fruiting in temperate forests in Yakushima, Japan
}

$\operatorname{AUTHOR}(S)$ :

Hanya, Goro; Aiba, Shin-ichiro

\section{CITATION:}

Hanya, Goro ...[et al]. Annual periodicity of fruiting in temperate forests in Yakushima, Japan. Forestry Studies in China 2011, 13(2): 112-122

\section{ISSUE DATE:}

2011-06

URL:

http://hdl.handle.net/2433/141942

\section{RIGHT:}

The final publication is available at www.springerlink.com; この論文は 著者最終稿です。内容が印刷版と異なることがありますので、引用の 際には出版社版をご確認ご利用ください。This is the Accepted Author Manuscript. Please cite only the published version. 
Fruiting phenology in Yakushima

\section{Abstract}

2 Fruiting phenology, assessed by seed fall, in five warm- and cool-temperate

3 forests on Yakushima, an island in southern Japan, were studied for 2 years in

4 one plot of $50 \mathrm{~m} \star 50 \mathrm{~m}$ and 4 years in four plots of $100 \mathrm{~m} \star 50 \mathrm{~m}$. The elevations

5 of the plots ranged 170-1200 m a.s.l. Seed fall phenology showed annual

6 periodicity in all of the plots. This was clear when assessed by the number of

$7 \quad$ species but became less clear when assessed by the biomass of seed fall.

8 Community-level annual periodicity was based on the prevalence of

9 population-level annual periodicity and interspecific synchronization of the

10 fruiting peak from autumn to winter. Fleshy fruits had peaks of seed fall in a

11 wider range of months than non-fleshy fruits, since it is sometimes beneficial to

12 bear fruit out of community-level fruiting peaks in order to avoid interspecific

13 competition for animal dispersers. No consistent effect of climatic factors on

14 seed fall phenology was detected.

15 Key words: fleshy fruits; fruit; frugivore; phenology; temperate forest 
Fruiting phenology in Yakushima

17 Fruit abundance and its seasonality are crucial factors in understanding the

\section{Introduction}

biomass and community structure of frugivores (Stevenson, 2001; Kissling et al., 2007). Studies on fruiting phenology have progressed in tropical forests, based on long-term monitoring of the entire tree community (Chapman et al., 1999; Anderson et al., 2005; Brearley et al., 2007). It has been found that various factors, such as temperature, rain fall and solar irradiance, affect patterns in fruiting phenology (Anderson et al., 2005; Zimmerman et al., 2007). These climatic factors show different seasonal patterns from region to region, and thus it is difficult to predict even the calendar month in which the fruiting peak will occur. On the contrary, fruiting patterns in temperate forests, as opposed to tropical rain forests, are referred to as 'clearly defined seasonal patterns' (Chapman et al., 1999). It is believed that the very regular, predictable changes in day length and coldness in winter force all of the plant species to follow an annual pattern of phenology (Newstrom et al., 1994). Data on multiple years are indispensable to examine whether annual periodicity is the norm in temperate forests. However, long-term data are surprisingly too scarce to conduct quantitative comparisons with tropical forests.

Animals respond to seasonal changes in food availability by various means, such as migration, hibernation, dietary switch (van Schaik et al., 1993), and food-storing behavior and/or physiology, such as scatter-hoarding and fat deposition (Jönsson, 1997). Annual periodicity in fruiting phenology, if it does exit, offers foods for frugivores in a predictable manner, in particular regarding the timing, and thus enables frugivores to adapt to seasonality easily. For example, in the case of fat deposition, if there were no annual periodicity, 
Fruiting phenology in Yakushima

animals would not be able to predict when to start depositing fat and how long the food shortage will last, and thus how much fat needs to be deposited. Therefore, annual periodicity is a crucial factor in fruiting phenology for the survival of frugivores.

Several questions need to be answered with regard to annual periodicity, assuming that annual periodicity is the norm in temperate forest. It remains an open question whether other climatic factors (e.g. rain fall, temperature and solar irradiance) also contribute to seasonality, such as in tropical forests (Anderson et al., 2005). Community-level phenology is the sum of various population-level phenology which reflects the adaptive strategy of an individual species, so analysis of population-level phenology is needed to explain community-level annual periodicity. We expect that community-level phenology becomes annually periodic when (1) population-level phenology is annually periodic, (2) population-level phenology synchronizes among species, and (3) duration of fruiting by individual species is short.

Temperate forests are also not uniform with respect to species composition, primary production and biomass. For example, coniferous forests in high elevation have comparatively larger basal area than broad-leaved forest (Aiba et al., 2007). Warm-temperate forests have similar characteristics with tropical forests when the warmth index is the same, such as species diversity, basal area, tree height, stem density and above ground biomass (Takyu et al., 2005). Considering these variations within temperate forest, it is necessary to cover both warm- and cool- (or coniferous) forests to clarify the general pattern in fruiting phenology in temperate forests. In this paper, we present data on fruiting phenology of two-four years 
Fruiting phenology in Yakushima

80

81

82

\section{(1)}

using seed fall data in five temperate forests on Yakushima Island, southern Japan, at different altitudes. The elevational gradient of this island covers both warm- and cool-temperate forests, and thus it is an ideal place to assess the degree of variability in fruiting phenology for temperate regions in general. First, we examined whether annual periodicity can be detected at the community level. Fleshy and non-fleshy species were examined separately because they have different meanings for frugivores and their phenology must have evolved under different selection pressures. Second, in order to assess the relative importance of annual periodicity compared with climate, the effects of both factors on fruiting phenology were examined. Third, in order to understand why community-level annual periodicity exists, we examine the annual periodicity at the population level of the main species. We explore the synchronization of fruiting peak among species and the duration of fruiting, which may enhance or disturb annual periodicity.

\section{Methods}

2 Study site

3 Yakushima is an island located in the southwestern part of Japan $\left(30^{\circ} \mathrm{N}, 131^{\circ} \mathrm{E}\right)$

that occupies an area of $503 \mathrm{~km}^{2}$, with the highest peak being $1936 \mathrm{~m}$ a.s.l.

The mean annual precipitation ranges from $2500 \mathrm{~mm}$ to $4700 \mathrm{~mm}$ along the coast and exceeds $8600 \mathrm{~mm}$ in the higher area (Eguchi, 1984). The mean annual temperature is $20^{\circ} \mathrm{C}$ in the lowland area (Tagawa, 1980) and $12.4^{\circ} \mathrm{C}$ at $1050 \mathrm{~m}$ a.s.l. (Hanya, 2004). Geological substrates are sedimentary in lowland areas, except in the western part, and granite in other parts. The vegetation of Yakushima is roughly classified as warm- and cool-temperate forests, having a 
Fruiting phenology in Yakushima

border at $1000 \mathrm{~m}$ a.s.I. Warm-temperate forests are dominated by evergreen broad-leaved trees (e.g., Castanopsis cuspidata, Quercus salicina, and Distylium racemosum), including some subtropical species, such as strangler figs (Ficus superba and F. microcarpa) in the lowland. Cool-temperate forests are coniferous forests, dominated by Cryptomeria japonica, Abies firma, and Tsuga sieboldii mixed with broad-leaved trees such as Quercus acuta, $Q$. salicina, and D. racemosum.

Study plots and seed litter collection

The following five vegetation plots were set in the primary forests of Yakushima.

Plots were named according to the location (eastern or western side) and altitude, such as E170, W280, E570, W1050, and E1200. The area was 0.25 ha $(50 \mathrm{~m} \star 50 \mathrm{~m})$ for W1050 and $0.5 \mathrm{ha}(100 \mathrm{~m} \star 50 \mathrm{~m})$ for others. Geological substrates are granite for W280, E570, W1050, and E1200 and sedimentary for E170. With regard to species composition, total litter fall and basal area, these plots can be regarded as representatives of each altitude/geological substrate (Aiba et al., 2007). All of the trees with a diameter at breast height (DBH) of more than $5 \mathrm{~cm}$ were recorded. Details of the plots are described in Aiba et al. (2007) and Table 1. The plots corresponded to Aiba et al.'s (2007) Y02Sa (E170), Y02Ga (W280), Y06Gb (E570), Y12Ga (W1050) and Y12Gc (E1200).

Since fruit fall phenology often differs from the ripe fruit availability in the canopy (Chapman et al., 1994), we analyze the seasonal pattern of seeds fallen separately from pulp (or other fruit part), which is presumably dispersed by animals, the wind, or other dispersal agents. In this way, we can remove the effect of fallen unripe fruits or old dehiscent fruits whose seeds have already 
Fruiting phenology in Yakushima

132 Climate

been dispersed long ago. In this paper, we refer 'seed' to only the seeds fallen separated from the pulp or other fruit parts, including broken seeds. For Fagaceae species, we regarded one acorn as a 'seed', because each acorn is a unit of dispersal. Acorns of Quercus salicina and Q. acuta could not be discriminated, so they were regarded as a single species. Except for acorns, most of the seeds were mature. Immature seeds were found mostly in a form surrounded by pulp and other fruit parts, and thus not included in this analysis. We set 25 (W1050) or 20 (other four plots) fruit traps, each with an area of $0.58 \mathrm{~m}^{2}, 1-1.5 \mathrm{~m}$ above the ground. Each trap consisted of a polyester cloth cone supported by a circular fiberglass frame. Each plot was divided into 25 (W1050) or 20 subplots and the traps were set in the center of the subplots. The collection period was August 1999-August 2001 in W1050 and July 1998-August 2002 in the other four plots. During that period, we collected seed litter once each month, usually in the latter half of that month. We oven-dried, sorted, and weighed the seeds for each species.

\section{Climatic data were taken at Yakushima Meteorological Station}

(http://www.jma.go.jp/jma/menu/report.html), which is in an eastern coastal village of Yakushima at $37 \mathrm{~m}$ a.s.l. Monthly averages of ambient temperature, daily minimum temperature, daily maximum temperature and monthly total rainfall and solar irradiance time were used for analysis. There is heterogeneity in climate throughout Yakushima; however, the inter-site differences in absolute values are not important in our analysis. The monthly or supra-annual variation patterns are expected to be more or less similar within the area of Yakushima. 
Fruiting phenology in Yakushima

141 Therefore, we used the record at Yakushima Meteorological Station as a proxy

142 of seasonal changes in climatic variables for all five study sites (see below). In

143 fact, monthly average temperature and precipitation in 2000 and 2001

144 significantly correlated between the station and near the W1050 plot (Hanya,

145 unpublished data) (temperature: $r=0.984, p<0.0001$; precipitation: $r=0.539$,

$146 \mathrm{p}=0.0038)$.

148 Data analysis

For the analysis of phenology, we analyzed the number of species and

150 the dry biomass of seed litter $(\mathrm{kg} / \mathrm{ha})$ in each month in each plot. Since the

151 collection was not conducted on the last day of each month, the biomass of seed

152 litter in that month was estimated assuming that the falling rate was constant

153 between the two collections. For the number of species of seeds, we used for

154 analysis the number of species found in the litter collected that month. In winter,

155 we sometimes failed to collect seed litter at E570 and E1200 because the traps

156 were filled with snow. If we failed to collect litter in month $\mathrm{X}$ due to heavy snow,

157 we removed the data of month $X$ and $X+1$ for the analysis of phenology. Seed

158 litter samples in E170 in February 2001 were lost by a postal accident. For the

159 analysis of seed fall phenology, the data of E170 in February 2001 was excluded

160 from the analysis.

162 generalized linear models (GLM) using cosine wave functions (Anderson et al., $1632005)$ with periodicities of 12 months having maximum values in either of the 12 164 months. For the number of species, we assumed Poisson distribution. For 165 the biomass of seed fall, we assumed normal distribution. The model having 
Fruiting phenology in Yakushima

the least AIC was selected, and if the model was significant $(p<0.05)$, we considered that there was a statistically significant annual periodicity.

For the community-level phenology, we tested the effects of both the annual periodicity and climatic factors. We used the cosine wave function, rainfall, average temperature, maximum temperature, minimum temperature and solar irradiance time as independent factors in the GLM. We examined the climatic data of not only the current month $X$ but also the average of the block of the past three months, namely, the average of the months of $\{(X-1)$ to $(X-3)\}$, $\{(X-4)$ to $(X-5)\}, \ldots$, and $\{(X-16)$ to $(X-18)\}$. We made three months block because (1) in order to make analysis simple, it is better to make the block length longer and (2) if the length of the block is longer than 3 months, each block would include very different two seasons (e.g. middle of summer and late autumn). We analyzed up to 18 months before because it was suggested that the fruit crop in autumn was affected by the temperature in summer of the preceding year, thus up to approximately 18 months before the fruiting peak in autumn to winter (Noma, 1997). We start from the simplest model using only one factor, such as the cosine wave function or a climatic factor, and we employed the model having the smallest AIC. Then, we added other factors and searched for the factor which decreased AIC the most. This procedure was repeated until the AIC did not further decrease by adding other factors. We used R 2.6.1. (C The R Foundation for Statistical Computing) for statistical analysis. We employed the Durbin-Watson statistic to test for temporal autocorrelation. If significant autocorrelation $(p<0.05)$ was found, an autoregressive order 1 covariance structure was incorporated in the model (Anderson et al., 2005). Although there was collinearity (correlations between 
Fruiting phenology in Yakushima

191

192

193

194

195

196

197

198

199

200

201

202

203

204

205

206

207

208

209

210

211

212

213

214

215

independent factors) among the independent variables, it was not a severe problem in this procedure because we examined only a few variables in a single model at any one time. In the models in which multiple independent variables were adopted, maximum variance inflation factors (VIF) were smaller (1.02-2.17) than the cut-off value (5) recommended in Neter et al. (2004).

\section{Results}

Seed fall phenology in Yakushima

Community-level seed fall showed annual periodicity, and seed fall peak tended to occur from December to January. Statistically significant annual periodicity was detected for the number of species in all plots and for both fleshy and non-fleshy fruits (Fig. 1). The peak of seed fall occurred in December and January for fleshy fruited species and in November, December and January for non-fleshy fruited species (Table 3a). The same tendency was apparent but became less clear when we analyzed the biomass of seed litter (Fig. 2). Annual periodicity was not significant for fleshy fruits in E170. The peak months of the biomass of seed litter occurred in more variable months from September to February (Table $3 b$ ). The $\mathrm{R}^{2}$ value in the GLM was significantly higher for the number of species than for the seed biomass (fleshy fruits: $t=4.14$, $p=0.014$; non-fleshy fruits: $t=4.39, p=0.012)$, indicating that annual periodicity was stronger for the number of species than for the seed biomass. Annual periodicity tended to be clearer for non-fleshy fruits than fleshy fruits at least for seed biomass, although the difference in $\mathrm{R}^{2}$ value was not significant $(\mathrm{t}=2.23$, $\mathrm{p}=0.089)$. Peak months were one or two months earlier in highland plots (W1050 and E1200) than others for fleshy fruits, but there was no such tendency 
Fruiting phenology in Yakushima

for non-fleshy fruits (Table 3).

Annual periodicity had a more consistent effect on seed fall phenology than climatic factors. We examined 20 GLMs ((5 plots) * (fleshy or non-fleshy) * (\#species or biomass of seeds)) on the effect of climate factors, annual periodicity and temporal autocorrelation on seed fall phenology. Among them, annual periodicity was adopted as a determining factor of seed fall phenology for 17 GLMs (Table 2). Among them, annual periodicity was the only factor (except for temporal autocorrelation) for 8 GLMs. Various climatic factors were adopted in each model; however, no factor consistently affected in the same direction. The maximum number of times that the same climatic factor was adopted in the same direction in different models was only two times.

At population level, annual periodicity was a prevailing pattern of seed fall. We examined annual periodicity for 49 populations of plants (Appendix). These populations constituted at least $1 \%$ of the seed fall biomass in each plot, and seed fall was observed twice (W1050) or four times (other plots). These populations belonged to 28 different species. Except for one species in one plot (Illicium anisatum, E1200), all showed statistically significant annual periodicity, and Illicium anisatum also showed significant annual periodicity in the two other plots (E570 and W1050). Fruiting peak occurred only from September to February for non-fleshy fruits, but fleshy fruits had peaks in a wider variety of months (Fig. 3): in March (Schefflera heptaphylla and Myrsine seguinii), May (Litsea acuminata), June (Machilus thunbergii and Myrica rubra) and August (Cornus macrophylla), to give some examples. Duration of seed fall tended to be shorter for fleshy fruits than for non-fleshy fruits. Seed fall lasted only for five months per year at maximum for 
Fruiting phenology in Yakushima

241

242

243

244

245

246

247

248

249

250

251

252

253

254

255

256

257

258

259

260

261

262

263

264

265

fleshy fruits, but it lasted for more than six months for some non-fleshy fruited species such as Stewartia monadelpha (E170: 10 mo), Tsuga sieboldii (W1050: 10 mo; E1200: 7 mo), Abies firma (W1050: 9 mo), Cryptomeria japonica (W1050: 8 mo), Quercus salicina/acuta (E170: 7 mo; W280: 9 mo; and E570: 9 mo), and Illicium anisatum (W1050: $6 \mathrm{mo}$ ). When all of the plots were combined, mean+SD of the months in which seed fall was observed per year was 3.6+1.1 months for fleshy fruits and 5.2+2.6 months for non-fleshy fruits $(t=2.4, p=0.019)$. This difference was also nearly significant when Fagaceae were excluded ( $t=2.0, p=0.058$; non-fleshy fruits: $4.8+2.5$ months). Therefore, the longer seed-fall duration of non-fleshy fruits than fleshy fruits could not be explained only by the fact that the seed-fall duration of Fagaceae was prolonged by the inclusion of unripe acorns.

\section{Discussion}

We showed that there was a clear annual periodicity in the seed fall phenology in all five forests of Yakushima. As we expected, the robust population-level annual periodicity was the basis for community-level annual periodicity. For the fruits that constituted at least $1 \%$ of the fruit fall, almost all of them showed statistically significant annual periodicity. Although annual periodicity is the norm in Yakushima, there are species which show non-annual patterns of fruiting. For example, Ficus superba and F. erecta populations continuously bear fruits throughout the year in the lowland forest in Yakushima (Agetsuma, 1995). However, no other species are known to show the same fruiting pattern and fruit production of these species is small and does not affect community-level fruiting phenology. For fleshy-fruited species, seed fall tended 
Fruiting phenology in Yakushima

to be earlier in highland plots than lowland plots, but there was no such tendency for non-fleshy fruited species. In highland plots, late fruiting of fleshy fruits may be disadvantageous due to damages by coldness or absence of frugivores (Hanya, 2005).

We also expected that community-level phenology would become annually periodic when population-level phenology synchronizes among species, and this expectation was also supported. Both fleshy and non-fleshy species tend to have their peak from autumn to winter, which is the same as the general pattern in temperate forest (Ting et al., 2008). The fact that non-fleshy species had stronger community-level annual periodicity than fleshy species may support our expectation, since non-fleshy species synchronized seed fall more strongly than did fleshy species. All of the species in temperate forests are under a common physical stress, such as low temperature and frostbite in winter (Debussche and Isenmann, 1992), and thus it is reasonable to synchronize the timing of fruiting among species. In addition, migrant frugivores migrate from high to low latitude and switch their diet from insectivory to frugivory, making it beneficial to bear fleshy fruits from autumn to winter (Thompson and Willson, 1979; Fuentes, 1992; Noma and Yumoto, 1997). However, the degree of synchrony was smaller for fleshy fruits, because some species have their peak in spring or summer. For non-fleshy fruits, there is no competition over dispersal agents, and thus they do not need to avoid overlapping fruiting. For fleshy fruits, it may sometimes be beneficial to bear fruits out of the community-wide fruiting peak to avoid inter-species competition for frugivores (Eriksson and Ehrlen, 1998). The species which bear fruits out of the autumn and winter are only a minority among the community, so community-level annual 
Fruiting phenology in Yakushima

291 periodicity is not affected so much if assessed by the number of species.

292 However, when assessed by the seed biomass, community-level annual

293 periodicity can be disturbed by the heavy fruiting of these few species (e.g. E170,

294 fleshy fruits).

We expected that the annual periodicity would become evident when the duration of fruiting by individual species becomes shorter. This expectation was not supported because non-fleshy species having a longer duration showed a stronger annual periodicity than fleshy species having a shorter duration. As long as the peak is synchronized among species, community-level seed fall phenology seems to become annually periodic even if individual species drop seeds for a long time. Some non-fleshy fruits dropped seeds for a prolonged period, such as for 10 months a year; however, all of these were wind-dispersed species or acorns. For acorns, unripe and ripe seeds were mixed in the results. For wind- and gravity-dispersed species, a small portion of seeds may have stayed in the canopy even after they became mature. timing and intensity of seed fall. However, these results do not negate the possibility that climate affects seed fall. At the coarse scale used in this study (month), the effects of annual periodicity in day length or temperature seem to be much stronger than other factors on the timing of seed fall. When assessed by

311 a finer scale, such as day, however, climate is known to affect phenology in 312 temperate forests (Lechowicz, 1995). In addition, annual periodicity, as a rule, 313 can only affect the timing and cannot affect the intensity of supra-annual 314 variations, which actually existed in Yakushima (Noma, 1997). Based on the 315 seven-year data in the W280 plot, Noma (1997) suggested that summer 
Fruiting phenology in Yakushima

temperature positively affected the intensity of fruiting in the next year, although the effect was also not statistically significant in his analysis. Consequently, four years might be too short to show the effect of climate statistically.

In conclusion, community-level seed fall phenology in Yakushima clearly showed annual periodicity, and this was based on the species-level annual periodicity and synchronization of fruiting among species from autumn to winter.

Fleshy-fruited species tended to have peaks of seed fall in more various months than non-fleshy fruited species, presumably because to reduce inter-species competition for frugivores.

\section{References}

Agetsuma N. 1995. Dietary selection by Yakushima macaques (Macaca fuscata yakui): the influence of food availability and temperature. Int J Primatol, 16:

\section{1-627}

Aiba S, Hanya G, Tsujino R, Takyu M, Seino T, Kimura K, Kitayama K. 2007. Comparative study of additive basal area of conifers in forest ecosystems along elevational gradients. Ecol Res, 22: 439-450

Anderson D P, Nordheim E V, Moermond T C, Gone Bi Z B, Boesch C. 2005. Factors influencing tree phenology in Taï National Park, Côte d'Ivoire. Biotropica, 37: 631-640

Brearley F Q, Proctor J, Suriantata, Nagy L, Dalrymple G, Voysey B C. 2007. Reproductive phenology over a 10-year period in a lowland evergreen rain forest of central Borneo. J Ecol, 95: 828-839

Chapman C A, Wrangham R, Chapman L J. 1994. Indexes of habitat-wide fruit 
Fruiting phenology in Yakushima

Chapman C A, Wrangham R W, Chapman L J, Kennard D K, Zanne A E. 1999. Fruit and flower phenology at two sites in Kibale National Park, Uganda. J Trop Ecol, 15: 189-211

Debussche M, Isenmann P. 1992. A Mediterranean bird disperser assemblage: composition and phenology in relation to fruit availability. Rev Ecol-Terre Vie, 47: $411-432$

Eguchi T. 1984. Climate of Yaku-shima Island, especially regionality of precipitation distribution. In: Nature Conservation Bureau E A, Japan (ed) Conservation Reports of the Yaku-shima Wilderness Area, Kyushu, Japan. Tokyo: Environment Agency. 3-26

352 Eriksson O, Ehrlen J. 1998. Phenological adaptations in fleshy vertebrate-dispersed fruits of temperate plants. Oikos, 82: 617-621

Fuentes M. 1992. Latitudinal and elevational variation in fruiting phenology among western European bird-dispersed plants. Ecography, 15: 177-183

Hanya G. 2004. Diet of a Japanese macaque troop in the coniferous forest of Yakushima. Int J Primatol, 25: 55-71

Hanya G. 2005. Comparisons of dispersal success between the species fruiting prior to and those at the peak of migrant frugivore abundance. Plant Ecol, 181: $167-177$

Jönsson K I. 1997. Capital and income breeding as alternative tactics of resource use in reproduction. Oikos, 78: 57-66

Kissling W D, Rahbek C, Bohning-Graese K. 2007. Food plant diversity as broad-scale determinant of avian frugivore richness. Proc R Soc B-Biol Sci, 274: $799-808$ 
Fruiting phenology in Yakushima

Lechowicz M J. 1995. Seasonality of flowering and fruiting in temperate forest trees. Can J Bot-Rev Can Bot, 73: 175-182

Neter J, Kutner M, Nachtsheim C, Wasserman W. 2004. Applied Linear Regression Models. 5th edition: McGraw-Hill/Irwin

Newstrom L E, Frankie G W, Baker H G. 1994. A new classification for plant phenology based on flowering patterns in lowland tropical rain forest trees at La Selva, Costa Rica. Biotropica, 26: 141-159

Noma N. 1997. Annual fluctuations of sapfruits production and synchronization within and inter species in a warm temperate forest on Yakushima Island. Tropics, 6: 441-449

Noma N, Yumoto T. 1997. Fruiting phenology of animal-dispersed plants in response to winter migration of frugivores in a warm temperate forest on Yakushima Island, Japan. Ecol Res, 12: 119-129

Stevenson P R. 2001. The relationship between fruit production and primate abundance in Neotropical communities. Biol J Linnean Soc, 72: 161-178

Tagawa H. 1980. Vegetation on the western slope of Mt. Kuniwaridake, Yakushima Island. Sci Rep Kagoshima Univ, 29: 121-137

Takyu M, Kubota Y, Aiba S, Seino T, Nishimura T. 2005. Pattern of changes in species diversity, structure and dynamics of forest ecosystems along latitudinal gradients in East Asia. Ecol Res, 20: 287-296

Thompson J N, Willson M F. 1979. Evolution of temperate fruit-bird interactions: phenological strategies. Evolution, 33: 973-982

Ting S, Hartley S, Burns K C. 2008. Global patterns in fruiting seasons. Glob Ecol Biogeogr, 17: 648-657

van Schaik C P, Terborgh J W, Wright S J. 1993. The phenology of tropical 
Fruiting phenology in Yakushima

391 forests: adaptive significance and consequences for primary consumers.

$392 \quad$ Annu Rev Ecol System, 24: 353-377

393 Zimmerman J K, Wright S J, Calderón O, Pagan M A, Paton S. 2007. Flowering

394 and fruiting phenologies of seasonal and aseasonal neotropical forests: the

395 role of annual changes in irradiance. J Trop Ecol, 23: 231-251

396

397

398 
Fruiting phenology in Yakushima

Table 1. Number of tree species, stems and total basal area in the five plots in Yakushima

\begin{tabular}{cccccc}
\hline \multirow{2}{*}{ Plot } & \multirow{2}{*}{ Altitude $(\mathrm{m})$} & \multirow{2}{*}{ Area (ha) } & \multicolumn{3}{c}{ Overall } \\
\cline { 4 - 6 } & & & \#Species & \#Stems & Basal area $\left(\mathrm{m}^{2} / \mathrm{ha}\right)$ \\
\hline E170 & 170 & 0.5 & $33(29,29)$ & 771 & 50.5 \\
W280 & 280 & 0.5 & $36(31,30)$ & 1290 & 53.1 \\
E570 & 570 & 0.5 & $32(30,25)$ & 1360 & 65.8 \\
W1050 & 1050 & 0.25 & 21 & 447 & 100 \\
E1200 & 1200 & 0.5 & $26(22,20)$ & 801 & 84.2 \\
\hline
\end{tabular}

*: Numbers in the parentheses indicate the value when the plot was divided into 399 two 0.25 ha subplots.

400 
Fruiting phenology in Yakushima

Table 2. Independent factors adopted in the best-fit generalized linear models on seed fall phenology

\begin{tabular}{|c|c|c|c|c|c|c|c|}
\hline \multirow{2}{*}{$\begin{array}{c}\text { \#Species/ } \\
\text { Seed amount } \\
\text { \#Species }\end{array}$} & \multirow{2}{*}{$\begin{array}{c}\begin{array}{c}\text { Fleshyl } \\
\text { Non-fleshy }\end{array} \\
\text { Fleshy }\end{array}$} & \multirow{2}{*}{$\begin{array}{l}\text { Plot } \\
\text { E170 }\end{array}$} & \multicolumn{5}{|c|}{ Adopted factos } \\
\hline & & & $+\mathrm{AN}$ & & & + SI16-18 & $+\mathrm{AR}$ \\
\hline \#Species & Fleshy & W280 & $+\mathrm{AN}$ & & & & \\
\hline \#Species & Fleshy & E570 & $+\mathrm{AN}$ & & & -SI16-18 & \\
\hline \#Species & Fleshy & W1050 & $+\mathrm{AN}$ & +RA4-6 & & & \\
\hline \#Species & Fleshy & E1200 & $+\mathrm{AN}$ & -RA13-15,-RA16-18 & & & \\
\hline \#Species & Non-fleshy & E170 & $+\mathrm{AN}$ & & & & \\
\hline \#Species & Non-fleshy & W280 & $+\mathrm{AN}$ & & & & \\
\hline \#Species & Non-fleshy & E570 & $+\mathrm{AN}$ & -RAO & & -SI10-12 & \\
\hline \#Species & Non-fleshy & W1050 & $+\mathrm{AN}$ & & & & \\
\hline \#Species & Non-fleshy & E1200 & $+\mathrm{AN}$ & & & & \\
\hline Seed amount & Fleshy & E170 & & & -AT10-12 & & \\
\hline Seed amount & Fleshy & W280 & $+\mathrm{AN}$ & -RA4-6 & & & $+\mathrm{AR}$ \\
\hline Seed amount & Fleshy & E570 & $+\mathrm{AN}$ & & & & $+\mathrm{AR}$ \\
\hline Seed amount & Fleshy & W1050 & $+\mathrm{AN}$ & -RA16-18 & & -SI4-6 & \\
\hline Seed amount & Fleshy & E1200 & & +RA4-6 & & & \\
\hline Seed amount & Non-fleshy & E170 & $+\mathrm{AN}$ & & & & $+\mathrm{AR}$ \\
\hline Seed amount & Non-fleshy & W280 & $+\mathrm{AN}$ & +RA,-RA13-15 & & -SI10-12 & $+A R$ \\
\hline Seed amount & Non-fleshy & E570 & $+\mathrm{AN}$ & & & & $+A R$ \\
\hline Seed amount & Non-fleshy & W1050 & & +RA4-6 & & & \\
\hline Seed amount & Non-fleshy & E1200 & $+\mathrm{AN}$ & -RAO & АTO & -SI4-6 & \\
\hline
\end{tabular}

AN: annual periodicity (cosine wave function having peak in the month indicated in Fig. 1 and Fig. 2), RA: rainfall, AT: average temperature, MX: maximum temperature, MN: minimum temperature, SI: solar irradiance time, AR: autoregressive factor Figures after the factors indicate the three months block. RAO denotes the rainfall of the current month, and RA1-3 denotes the rainfall 1-3 months before the current months.

Bold: significant factors $(\mathrm{p}<0.05)$

$401+/$ - before the factor indicates the direction of the regression. 
Fruiting phenology in Yakushima

Table 3. Peak months of seed fall

a. Number of species

\begin{tabular}{|c|c|c|}
\hline Site & $\begin{array}{c}\text { Fleshy fruited } \\
\text { species }\end{array}$ & $\begin{array}{l}\text { Non-tlesny } \\
\text { fruited } \\
\text { snecies }\end{array}$ \\
\hline E170 & January & November \\
\hline W280 & January & November \\
\hline E570 & December & January \\
\hline W1050 & December & December \\
\hline E1200 & December & January \\
\hline \multicolumn{3}{|c|}{ b. Biomass of seed fall } \\
\hline Site & $\begin{array}{c}\text { Fleshy fruited } \\
\text { species }\end{array}$ & $\begin{array}{c}\text { Non-fleshy } \\
\text { fruited }\end{array}$ \\
\hline E170 & January* & December \\
\hline W280 & February & September \\
\hline E570 & January & December \\
\hline W1050 & November & December \\
\hline E1200 & November & February \\
\hline
\end{tabular}

*: Annual periodicity not significant 
Fruiting phenology in Yakushima

404 Legends to the figures

405 Fig. 1. Seasonal variations in the number of species of seed fall. Best-fit

406 cosine curve was drawn and the peak months were indicated in the headers.

$407 \quad$ Y-axis is the number of species. Note that the scale is different among

408 graphs. Data were not available for the months indicated as asterisks. $\mathrm{R}^{2}$

$409 \quad$ values indicate the proportion that the seasonal variation in seed fall

410 phenology is explained by the annual periodicity (cosine wave function).

411 Left (filled bars): fleshy fruits, right (open bars): non-fleshy fruits.

412 Fig. 2. Seasonal variations in the biomass of seed fall. Y-axis is $\mathrm{kg} / \mathrm{ha}$. See $413 \quad$ legends for Fig. 1.

414 Fig. 3. Number of species whose seed fall peak occurred in each calendar 415 months. Filled bars: fleshy fruits, open bars: non-fleshy fruits. Height of 416 the bars is the number of species. 
Fruiting phenology in Yakushima

(a) E170, fleshy: January, $\left(\mathrm{R}^{\wedge} 2=0.56\right)$

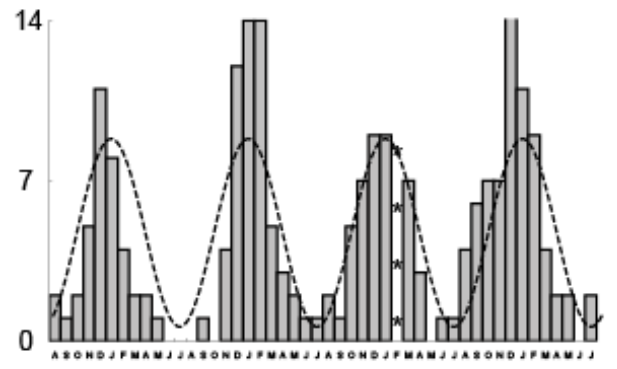

(c) W280, fleshy: January, $\left(R^{\wedge} 2=0.63\right)$

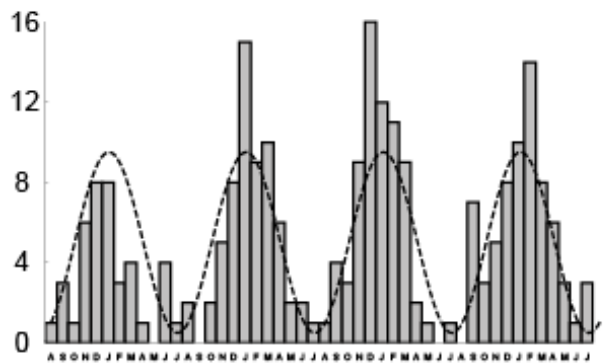

(e) E570, fleshy: December, $\left(R^{\wedge} 2=045\right)$

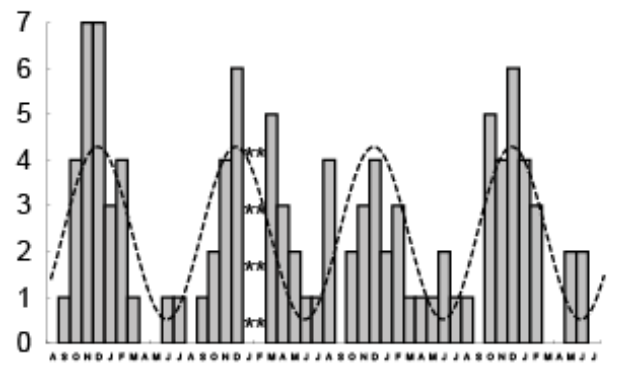

(g) W1050, fleshy: December, $\left(R^{\wedge} 2=0 / 49\right)$ 6

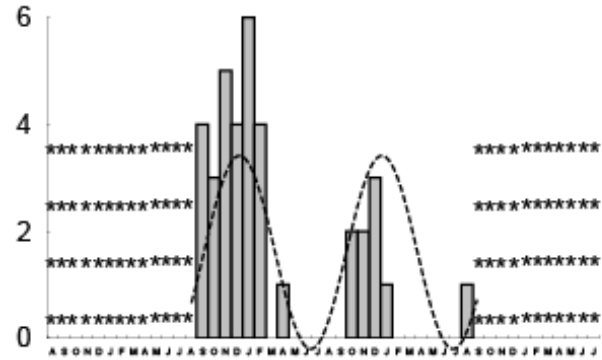

(i) $\mathrm{E} 1200$, fleshy: December, $\left(\mathrm{R}^{\wedge} 2=0.22\right)$

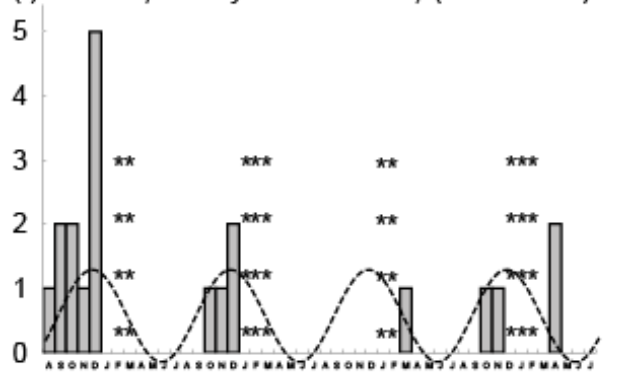

(b) E170, non-fleshy: November, $\left(R^{\wedge} 2=0.65\right)$

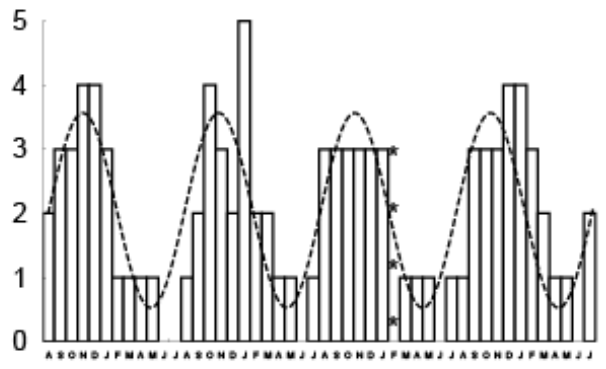

(d) W280, non-fleshy: November, $\left(R^{\wedge} 2=0.33\right)$

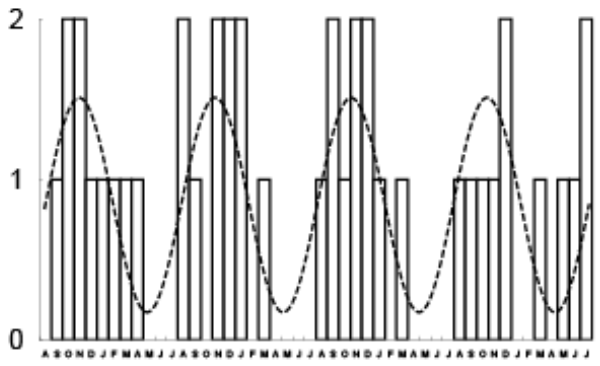

(f) E570, non-fleshy: January, $\left(R^{\wedge} 2=0.45\right)$

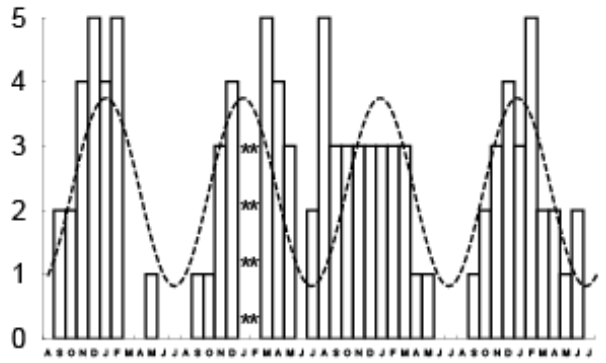

(h) W1050, non-fleshy: December, $\left(R^{\wedge} 2=0.37\right)$

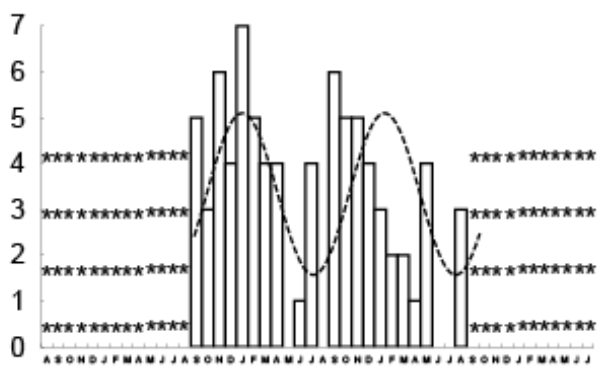

(j) E1200, non-fleshy: January, $\left(R^{\wedge} 2=0.38\right)$

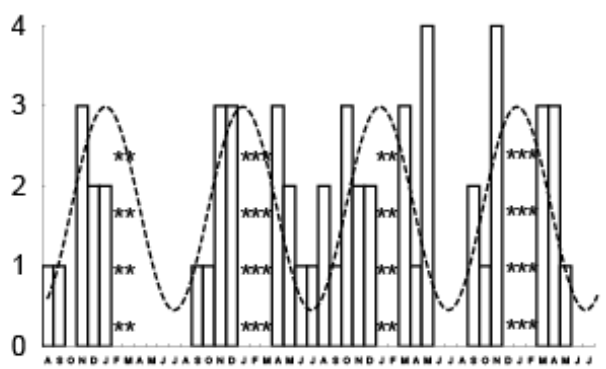

Fig. 1 
Fruiting phenology in Yakushima

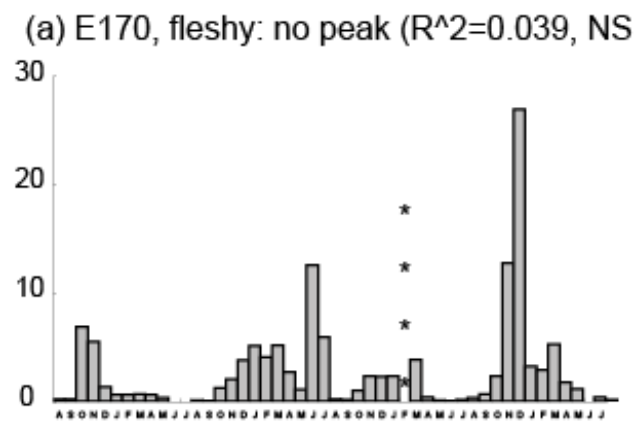

(c) W280, fleshy: February, $\left(R^{\wedge} 2=0.13\right)$

25

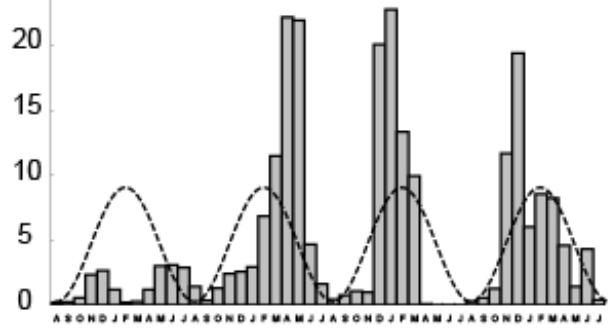

(e) E570, fleshy: January, $\left(R^{\wedge} 2=0.085\right)$

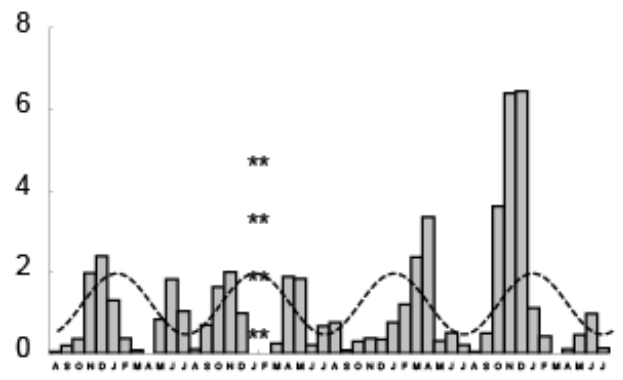

(g) W1050, fleshy: November, $\left(R^{\wedge} 2=0.31\right)$ 1.5

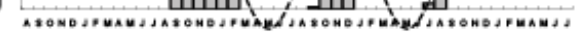

(i) $\mathrm{E} 1200$, fleshy: November, $\left(\mathrm{R}^{\wedge} 2=0.099\right)$

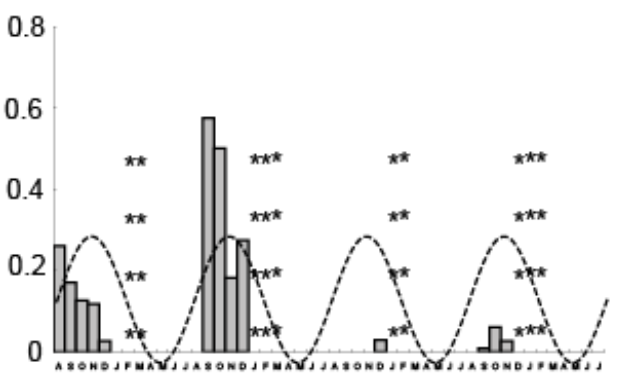

(b) $\mathrm{E} 170$, non-fleshy: December, $\left(\mathrm{R}^{\wedge} 2=0.32\right)$

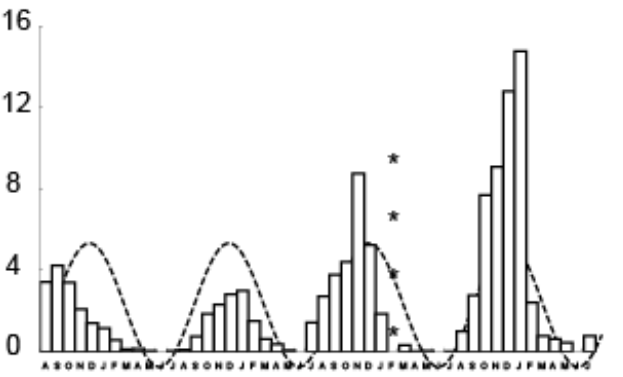

(d) W280, non-fleshy: September, $\left(R^{\wedge} 2=0.19\right)$

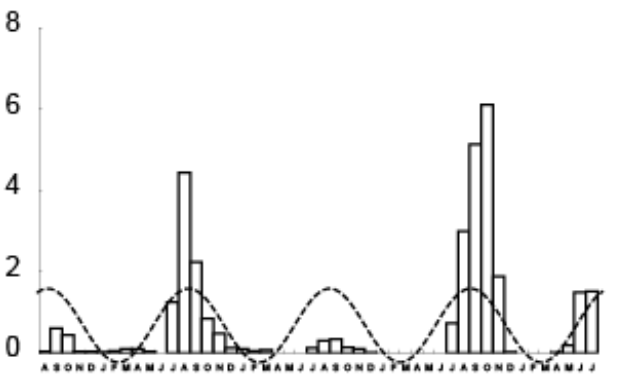

(f) $\mathrm{E} 570$, non-fleshy: December, $\left(\mathrm{R}^{\wedge} 2=0.20\right)$ 2.5

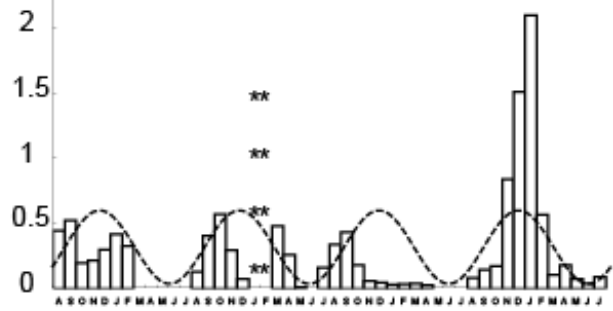

(h) W1050, non-fleshy: December, $\left(R^{\wedge} 2=0.30\right)$ 20

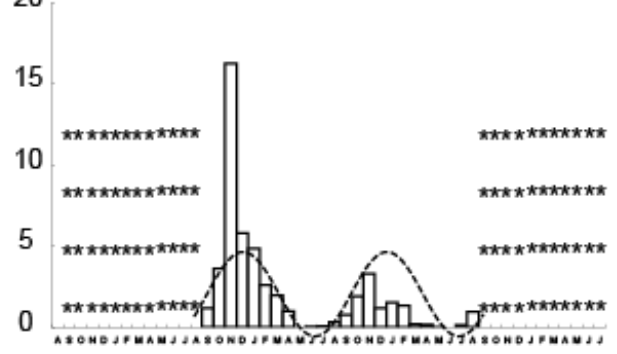

(j) E1200, non-fleshy: December, $\left(R^{\wedge} 2=0.19\right)$

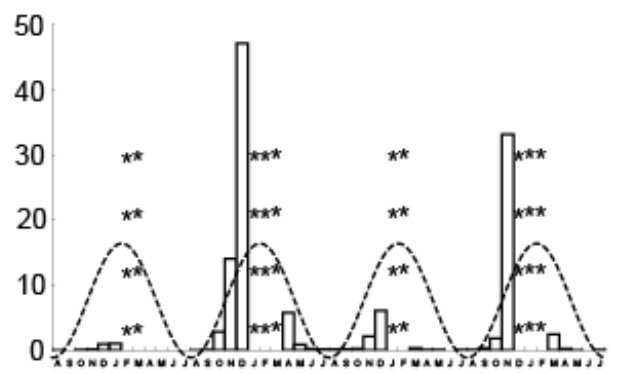

Fig. 2 
Fruiting phenology in Yakushima

(a) E170

D

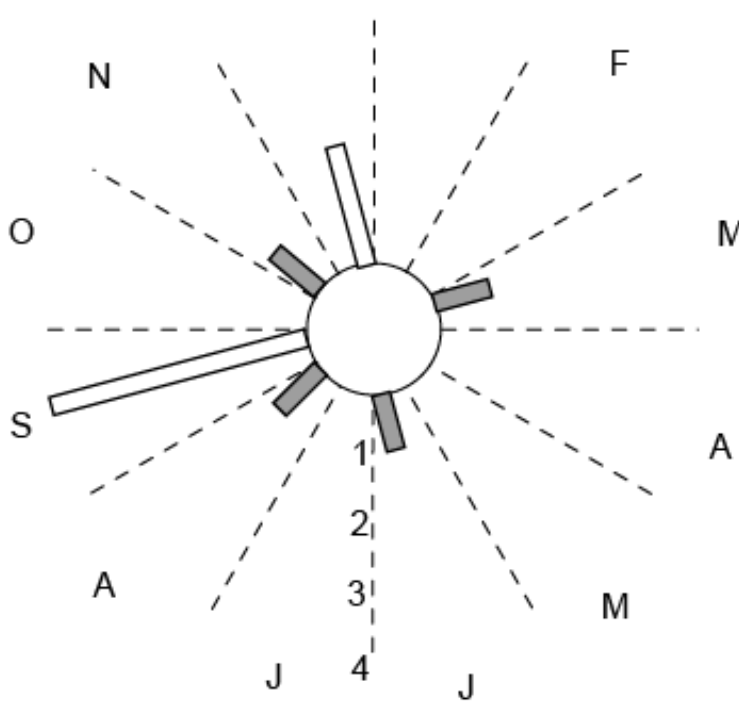

(c) E570

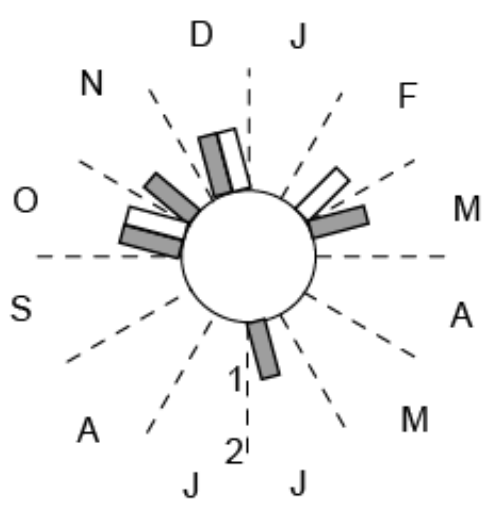

(e) E1200
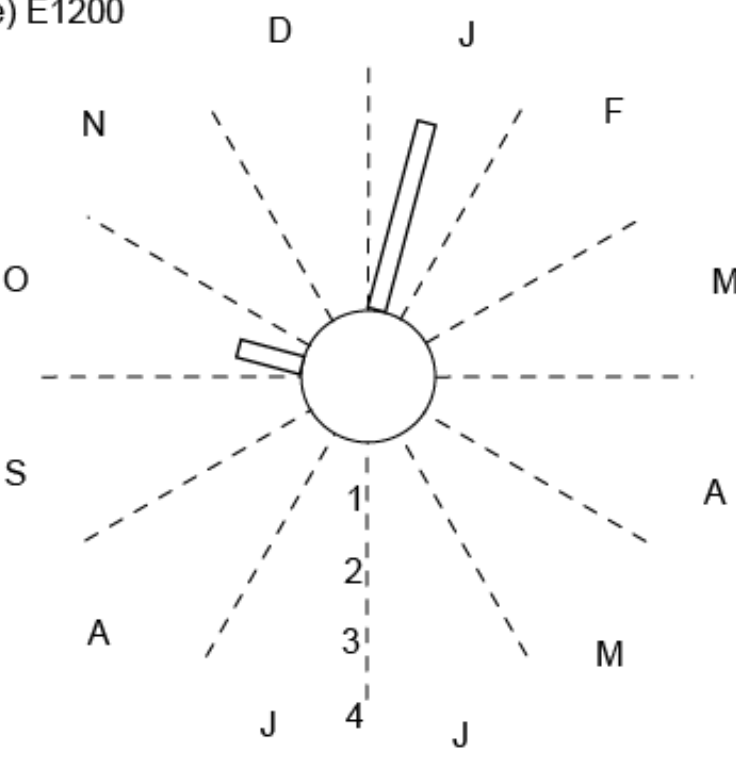

(b) W280

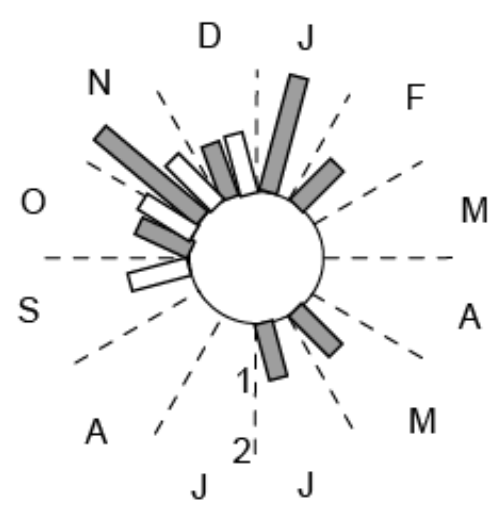

(d) $\mathrm{W} 1050 \mathrm{D} \quad \mathrm{J}$

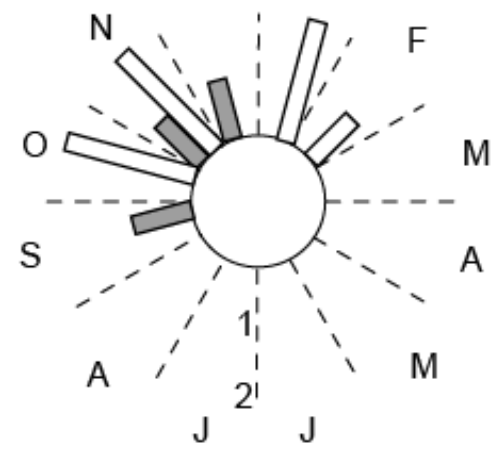

$425 \quad$ Fig. 3 
Fruiting phenology in Yakushima

Appendix. Peak months and duration of seed fall of main species

(a) E170

\begin{tabular}{llccc}
\hline Family & \multicolumn{1}{c}{ Species } & $\begin{array}{c}\text { Fleshy } \\
\text { /Non- } \\
\text { fleshy }\end{array}$ & $\begin{array}{c}\text { Duration of } \\
\text { Peakth }\end{array}$ & $\begin{array}{c}\text { seed fall } \\
\text { (\#months/ } \\
\text { year) }\end{array}$ \\
\hline Theaceae & Stewartia monadelpha & $\mathrm{N}$ & Dec & 9.5 \\
Fagaceae & Quercus salicina & $\mathrm{N}$ & Dec & 7 \\
Theaceae & Camellia japonica & $\mathrm{N}$ & Sep & 4 \\
Magnoliaceae & Michelia compressa & $\mathrm{N}$ & Sep & 1.5 \\
Hamamelidaceae & Distylium racemosum & $\mathrm{N}$ & Sep & 4 \\
Lauraceae & Neolitsea sericea & $\mathrm{F}$ & Nov & 3 \\
Lauraceae & Machilus thunbergii & $\mathrm{F}$ & Jun & 1 \\
Theaceae & Camellia sasanqua & $\mathrm{N}$ & Sep & 2 \\
Cornaceae & Cornus macrophylla & $\mathrm{F}$ & Aug & 0.5 \\
Araliaceae & Schefflera heptaphylla & $\mathrm{F}$ & Mar & 2 \\
\hline
\end{tabular}

(b) W280

\begin{tabular}{llccc}
\hline \multicolumn{1}{c}{ Family } & \multicolumn{1}{c}{ Species } & $\begin{array}{c}\text { Fleshy } \\
\text { /Non- } \\
\text { fleshy }\end{array}$ & $\begin{array}{c}\text { Peak } \\
\text { month }\end{array}$ & $\begin{array}{c}\text { Duration of } \\
\text { seed fall } \\
\text { (\#months/ } \\
\text { year) }\end{array}$ \\
\hline Fagaceae & Quercus salicina & N & Nov & 9.25 \\
Lauraceae & Neolitsea aciculata & F & Nov & 3.5 \\
Theaceae & Ternstroemia gymnanthera & F & Oct & 4.25 \\
Myrsinaceae & Ardisia sieboldii & F & Jan & 4 \\
Lauraceae & Litsea acuminata & F & May & 3.25 \\
Fagaceae & Lithocarpus edulis & N & Oct & 2.75 \\
Theaceae & Cleyera japonica & F & Jan & 4.25 \\
Lauraceae & Machilus thunbergii & F & Jun & 3.25 \\
Lauraceae & Neolitsea sericea & F & Dec & 3.75 \\
Fagaceae & Castanopsis sieboldii & N & Sep & 2 \\
Symplocaceae & Symplocos prunifolia & F & Nov & 5 \\
Hamamelidaceae & Distylium racemosum & N & Dec & 2.25 \\
Myrsinaceae & Myrsine seguinii & F & Feb & 4.5 \\
\hline
\end{tabular}

(c) E570

\begin{tabular}{llccc}
\hline \multicolumn{1}{c}{ Family } & \multicolumn{1}{c}{ Species } & $\begin{array}{c}\text { Fleshy } \\
\text { /Non- } \\
\text { fleshy }\end{array}$ & $\begin{array}{c}\text { Deak } \\
\text { month }\end{array}$ & $\begin{array}{c}\text { Deed fall } \\
\text { (\#months/ } \\
\text { year) }\end{array}$ \\
\hline Fagaceae & Quercus salicina/acuta & $\mathrm{N}$ & Sep & 8.5 \\
Myricaceae & Myrica rubra & $\mathrm{F}$ & Jun & 3 \\
Theaceae & Stewartia monadelpha & N & Dec & 5 \\
Myrsinaceae & Myrsine seguinii & F & Mar & 4.25 \\
Symplocaceae & Symplocos prunifolia & F & Dec & 5.25 \\
Pinaceae & Tsuga sieboldii & N & Feb & 4.75 \\
Illiciaceae & Illicium anisatum & N & Oct & 1.5 \\
Lauraceae & Neolitsea aciculata & F & Nov & 1.5 \\
Theaceae & Ternstroemia gymnanthera & F & Oct & 2.5 \\
\hline
\end{tabular}


Fruiting phenology in Yakushima

(d) W1050

\begin{tabular}{llccc}
\hline \multicolumn{1}{c}{ Family } & \multicolumn{1}{c}{ Species } & $\begin{array}{c}\text { Fleshy } \\
\text { /Non- } \\
\text { fleshy }\end{array}$ & $\begin{array}{c}\text { Deak } \\
\text { month }\end{array}$ & $\begin{array}{c}\text { seed fall } \\
\text { (\#months/ } \\
\text { year) }\end{array}$ \\
\hline Cupressaceae & Cryptomeria japonica & N & Jan & 10 \\
Pinaceae & Abies firma & N & Nov & 8.5 \\
Pinaceae & Tsuga sieboldii & N & Feb & 5 \\
Hamamelidaceae & Distylium racemosum & N & Nov & 5.5 \\
Theaceae & Stewartia monadelpha & N & Jan & 5 \\
Fagaceae & Quercus salicina/acuta & N & Oct & 5.5 \\
Symplocaceae & Symplocos tanakae & F & Jan & 1 \\
Illiciaceae & Illicium anisatum & N & Oct & 7.5 \\
Araliaceae & Dendropanax trifidus & F & Nov & 2 \\
Symplocaceae & Symplocos myrtacea & F & Sep & 2 \\
Theaceae & Cleyera japonica & F & Dec & 4.5 \\
\hline
\end{tabular}

(e) E1200

\begin{tabular}{llccc}
\hline Family & \multicolumn{1}{c}{ Species } & $\begin{array}{c}\text { Fleshy } \\
\text { /Non- } \\
\text { fleshy }\end{array}$ & $\begin{array}{c}\text { Peak } \\
\text { month }\end{array}$ & $\begin{array}{c}\text { Duration of } \\
\text { seed fall } \\
\text { (\#months/ } \\
\text { year) }\end{array}$ \\
\hline Pinaceae & Tsuga sieboldii & $\mathrm{N}$ & Jan & 6.5 \\
Pinaceae & Abies firma & $\mathrm{N}$ & Jan & 5.5 \\
Cupressaceae & Cryptomeria japonica & $\mathrm{N}$ & Jan & 2.5 \\
Theaceae & Camellia japonica & $\mathrm{N}$ & Oct & 1.5 \\
Fagaceae & Quercus salicina/acuta & $\mathrm{N}$ & Aug & 4.5 \\
Illiciaceae & Illicium anisatum & $\mathrm{N}$ & Nov $^{*}$ & 4.5 \\
\hline
\end{tabular}

F: fleshy-fruits; $\mathrm{N}$ : non-fleshy-fruits

*: Annual periodicity not significant 